\title{
Formation of humic acids in lignites and subbituminous coals by dry air oxidation
}

\author{
Mercedes Estévez, Roberto Juan, Carmen Ruiz and José M. Andrés \\ Instituto de Carboquímica, C.S.I.C., Pza. Paraiso no. 4, Apdo 589, Zaragoza, Spain \\ (Received 20 January 1989; revised 16 October 1989)
}

\begin{abstract}
A study of dry oxidation of coals by air has been performed. Four Spanish coals, ranging from lignite to subbituminous, were studied at three moderate temperatures for two different periods of time. The main goal with respect to possible use as fertilizers was to increase the humic acid content of the above-mentioned coals. The best results for humic acid production were obtained at the highest temperatures and after longer times. Lower-rank coals yielded the highest humic acid contentrations, but due to the severe loss of weight of these coals, the nett increase was lower than that obtained from subbituminous coals. A detailed study of the elemental composition of the coals, the generation of oxygenated functional groups and the molecular size of humic acids is reported. The evolution of sulphur forms during the process is also described.
\end{abstract}

(Keywords: coal; humic acids; oxidation)

Much work has been done on the oxidation of coal. The three main goals of this research were to explain the occurrence of autoignition ${ }^{1}$; the destructive oxidation of coal as method for gathering structural information; and the conversion of coal to coal acids ${ }^{2}$ (e.g. aromatic polycarboxylic acids) or humic acids (HA) intended for use as fertilizers ${ }^{3}$. Recently, the formation of acidic groups followed by air oxidation at moderate temperatures was proposed as a pretreatment for preparing calcium ion-exchanged coals used as desulphurizing agents in combustion ${ }^{4}$.

The purpose of this paper is to study the aerial oxidation of coal with a view to producing HA, the most active constituent of coal from an edaphological point of view. Atmospheric oxygen is used for coal oxidation because it is the cheapest and most readily available oxidant.

During the course of coal oxidation in a stream of air, the characteristics of the substances obtained depend on the nature of the coal and on the reaction conditions used. This paper studies the influence of reaction time $(t)$, temperature $(T)$ and coal rank on the formation of HA and functional groups in oxidized samples of four Spanish coals. To ensure a systematic study, factorial techiques were used to screen the above-mentioned variables and to facilitate the construction of a statistically significant model. The oxidized coal samples were examined for changes in HA content, elemental composition and phenolic and carboxylic acidities. The HA from these oxidized coal samples were also tested for variations in the ratio of optical densities at 465 and $665 \mathrm{~nm}\left(\mathrm{E}_{4} / \mathrm{E}_{6}\right.$ ratio). Taking into account the experimental results, additional experiments were carried out at a higher temperature.

\section{EXPERIMENTAL}

The coals used were two lignites from Arenas del Rey (A) and Puentes de García Rodríguez (P) and two subbituminous coals from Estercuel (E) and Berga (B). They were ground to pass a $0.25 \mathrm{~mm}$ sieve. Table 1 shows their proximate and ultimate analyses and their IIA content determined by the method described below.

Prior to oxidation, the finely ground coals were partially demineralized and debitumenized to avoid the possible catalytic effect of mineral matter on oxidation, and to eliminate the most aliphatic and oxidationresistant coal fractions, respectively. Demineralization was carried out by suspension of the coal in $0.5 \mathrm{~N} \mathrm{HCl}$ $(1: 10 \mathrm{w} / \mathrm{v})$ for $1 \mathrm{~h}$ at ambient temperature, with mechanical stirring. Debitumenization was performed in a Soxhlet extractor using ethanol-benzene $(1: 1 \mathrm{v} / \mathrm{v})$ mixture until no extraction was detected.

The samples $(\approx 10 \mathrm{~g})$ were placed in an air-drying oven in $14 \mathrm{~cm}$ i.d. sieves, with a nylon mesh bottom $(\approx 20 \mu \mathrm{m})$ to allow air circulation. The sieves were stirred daily to avoid heterogeneity.

A $2^{2}$ factorial design, requiring four runs, was used. The runs were replicated to calculate the standard error. The design matrix, factor levels and \% $\mathrm{HA}$ are shown in Table 2.

Elemental analyses $(\mathrm{C}, \mathrm{H}, \mathrm{N})$, total sulphur and sulphur forms were determined. Oxygen was calculated by difference. The HA were extracted by suspending the coal in $0.5 \mathrm{~N} \mathrm{NaOH}(1: 10 \mathrm{w} / \mathrm{v})$ in inert atmosphere, at ambient temperature and with mechanical stirring overnight. The suspension was centrifuged and the supernatant was used for subsequent analyses. For coals $E$ and $B$, an additional filtration step was used after centrifugation. The HA content was measured colorimetrically at $450 \mathrm{~nm}$ in solutions buffered at $\mathrm{pH} 9$. Calibration lines were performed for the HA from each coal oxidized at 120,150 and $190^{\circ} \mathrm{C}$.

Carboxyl groups and total acidity were determined with barium acetate and barium hydroxide, respectively, using Schafer's methods ${ }^{5,6}$, and phenolic groups were calculated by difference. The ratio of optical densities at 465 and $665 \mathrm{~nm}\left(\mathrm{E}_{4} / \mathrm{E}_{6}\right)$ was measured on $\mathrm{HA}$ solutions 
(1-2 $\mathrm{g} \mathrm{L}^{-1}$ ) at $\mathrm{pH} 7-8$ according to the method proposed by Chen et al.?.

\section{RESULTS AND DISCUSSION}

The results from the factorial-design experiments are shown in Table 2. The values were fitted to the following equation:

$$
y=b_{0}+b_{1} X_{1}+b_{2} X_{2}+b_{12} X_{1} X_{2}
$$

where $y$ is the response and $X_{\mathrm{i}}$ are coded values of the factors. Only the coefficients with a significance higher than $95 \%$ were considered for the equations obtained ${ }^{8}$.

\section{Mathematical models}

A $\% \mathrm{HA}=47.69+4.41 X_{1}+8.01 X_{2}$

P $\% \mathrm{HA}=51.32+4.46 X_{2}$

$\mathrm{E}$ there is no significant cocfficient

B $\% \mathrm{HA}=2.93+1.94 X_{1}+2.16 X_{2}+1.55 X_{1} X_{2}$

The results obtained from coals $A$ and $P$ are perfectly fitted to a linear model and the most influential factor is time. Temperature influences coal $\mathrm{A}$ but not $\mathrm{P}$, because coal $\mathrm{A}$ is younger and so more susceptible to undergoing thermal decomposition. Coal $\mathrm{E}$ results can be explained statistically by a normal distribution around the average, exhibiting no influence of the considered variables. All the coefficients obtained for coal B are significant, as is the fit, but due to the extraordinarily low standard error and HA contents, they should be considered with caution.

At the highest temperature and time levels there is a strong increase in \% $\mathrm{HA}$. It is likely that, in addition to an oxidation of the aliphatic fraction, which produces shorter molecular fragments and carboxylic groups, an oxidation of the aromatic fraction takes place with

Table 1 Analysis of parent coals

\begin{tabular}{lrrrr}
\hline & Coal A & Coal P & Coal E & Coal B \\
\hline $\begin{array}{l}\text { Proximate analysis (wt \%) } \\
\quad\end{array}$ & & & \\
Moisture & 9.63 & 7.70 & 7.56 & 5.74 \\
Ash & 5.40 & 32.18 & 20.81 & 10.57 \\
Volatile matter & 46.35 & 32.24 & 27.81 & 30.41 \\
Fixed carbon & 38.62 & 27.88 & 43.82 & 53.28 \\
Ultimate analysis (daf) & & & & \\
\%C & 60.91 & 61.36 & 72.49 & 75.38 \\
\%H & 4.15 & 5.20 & 4.37 & 4.88 \\
\%N & 0.88 & 0.77 & 0.64 & 1.23 \\
\%So & 6.35 & 3.33 & 2.09 & 5.17 \\
\%O diff & 27.71 & 29.34 & 20.41 & 13.34 \\
\%Humic acids (daf) & 47.92 & 50.71 & 11.51 & 0.30 \\
\hline
\end{tabular}

formation of phenolic groups, with a reaction rate lower than that of the first process.

Coal A has the highest concentration of HA after oxidation at the highest temperature and time levels, as well as one of the largest initial HA contents. Coal A is, apparently, the most adequate of the four studicd samples for producing humic acids. The model is statistically valid only in the range studied: e.g. by increasing the temperature, combustion of the sample would be obtained and organic matter (and hence HA) would disappear. However, Table 2 shows that the best results are obtained for the highest temperature and longest time and that the effect of the temperature is very strong for longer times, so the equations obtained are misleading ${ }^{8,9}$. Our experience indicated that times longer than 10 days did not have effect on the $\% \mathrm{HA}$, so, to obtain more information about the evolution of the oxidation with the temperature, additional experiments were carried out at $190^{\circ} \mathrm{C}$. This temperature was chosen as a high limit because $195^{\circ} \mathrm{C}$ was the ignition point for coal $\mathrm{B}$.

A loss of weight was observed for all samples during the oxidation so, in addition to the ultimate analysis of the end products (10 days), complete matter balances were computed. The mass variation of weight, weight of HA extracted, carbon, hydrogen, nitrogen, total sulphur and oxygen, calculated for an initial weight of coal sample (daf) of $100 \mathrm{~g}$, is shown in Figure 1. The addition of the variations due to each element $(\mathrm{C}, \mathrm{H}, \mathrm{N}, \mathrm{S}, \mathrm{O})$ accounts for the total variation in weight of the sample.

Table 3 Main oxygenated functional groups

\begin{tabular}{llllr}
\hline Coal samples & COOH & $\delta$ meq $^{a}$ & phenolic & $\delta$ meq $^{a}$ \\
\hline A & 3.10 & & 3.75 & \\
A-120 & 3.36 & 0.13 & 3.84 & -0.05 \\
A-150 & 4.42 & 1.26 & 4.55 & 0.74 \\
A-190 & 5.94 & 0.76 & 6.87 & 0.71 \\
P & 2.15 & & 5.33 & \\
P-120 & 2.44 & 0.22 & 4.49 & -0.97 \\
P-150 & 3.84 & 1.70 & 4.75 & -0.57 \\
P-190 & 6.60 & 2.69 & 8.65 & 1.02 \\
E & 0.61 & & 4.16 & \\
E-120 & 1.02 & 0.40 & 5.98 & 1.79 \\
E-150 & 2.87 & 2.39 & 6.62 & 2.76 \\
E-190 & 5.28 & 4.19 & 6.54 & 1.78 \\
B & 0.06 & & 1.37 & \\
B-120 & 0.19 & 0.13 & 3.33 & 1.95 \\
B-150 & 1.35 & 1.36 & 4.43 & 3.28 \\
B-190 & 4.48 & 4.17 & 5.70 & 4.02 \\
\hline
\end{tabular}

Values in meq/g of coal (daf)

${ }^{a} \delta \mathrm{meq}$ corresponds to the absolutc variation (in meq) of the functional group considered for $1 \mathrm{~g}$ of coal (daf)

Table 2 Design matrix and results in \%humic acids

\begin{tabular}{|c|c|c|c|c|c|c|c|c|}
\hline \multirow[b]{2}{*}{ Exp. } & \multirow[b]{2}{*}{$X_{1}$} & \multirow[b]{2}{*}{$\mathrm{T}\left({ }^{\circ} \mathrm{C}\right)$} & \multirow[b]{2}{*}{$\mathrm{X}_{2}$} & \multirow[b]{2}{*}{$\mathrm{t}$ (days) } & \multicolumn{4}{|c|}{$\mathrm{HA}^{a}(\%)$} \\
\hline & & & & & Coal A & Coal P & Coal E & Coal B \\
\hline 1 & -1 & 120 & -1 & 1 & 39.29 & 48.01 & 7.14 & 0.38 \\
\hline 2 & -1 & 120 & +1 & 10 & 47.20 & 53.61 & 10.09 & 1.60 \\
\hline 3 & +1 & 150 & -1 & 1 & 40.07 & 45.71 & 9.07 & 1.16 \\
\hline 4 & +1 & 150 & +1 & 10 & 64.13 & 57.97 & 20.60 & 8.58 \\
\hline \multicolumn{5}{|c|}{ Experimental error $\left(\sigma^{2}\right)$} & 10.22 & 10.48 & 10.05 & 0.60 \\
\hline
\end{tabular}

a daf basis 

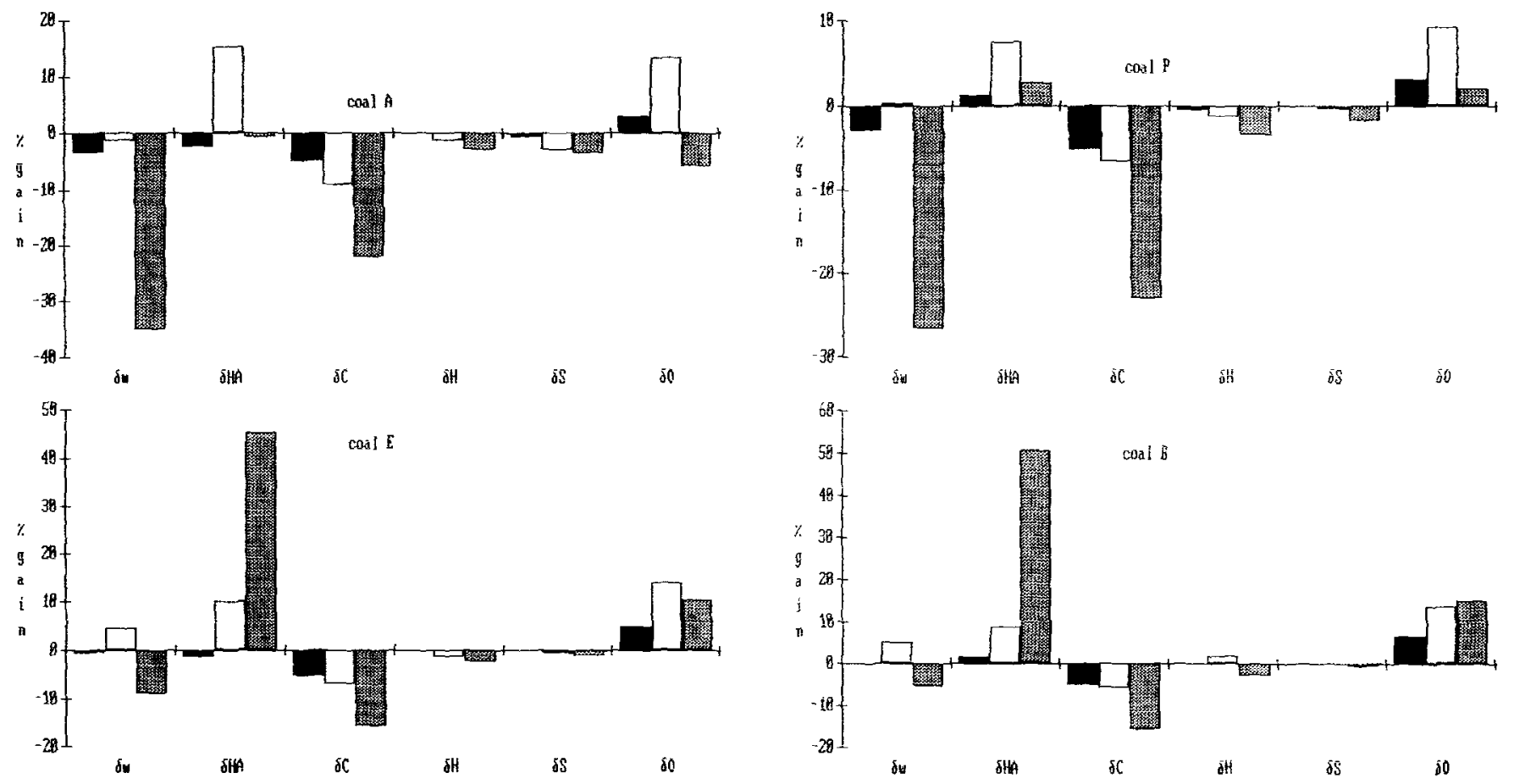

$120^{\circ} \mathrm{C} \square 150^{\circ} \mathrm{C} \quad \mathrm{F}^{2} 198^{\circ} \mathrm{C}$

Figure 1 Variation of weight, weight of HA extracted, and elemental composition calculated for $100 \mathrm{~g}$ of coal sample (daf)

Lower-rank coals (A and P) undergo a small loss of weight $\delta w$ at 120 and $150^{\circ} \mathrm{C}$ and a higher one at $190^{\circ} \mathrm{C}$. The behaviour of the higher-rank coals ( $E$ and $B$ ) is different, with a negligible loss of weight at $120^{\circ} \mathrm{C}$, a significant increase at $150^{\circ} \mathrm{C}$ and a decrease of the same order of magnitude at $190^{\circ} \mathrm{C}$. A more detailed explanation can be given considering the individual matter balance for each element.

\section{Carbon and hydrogen $(\delta C$ and $\delta H)$}

At 120 and $150^{\circ} \mathrm{C}$, the losses in carbon and hydrogen content are similar for all the coals. At $190^{\circ} \mathrm{C}$ the loss of hydrogen is the same in the four samples but the decrease in the carbon content is 1.5 times greater in lignites than in subbituminous coals. In all cases, the $\mathrm{H} / \mathrm{C}$ ratio decreases with temperature by hydrogen elimination as water $^{10,11}$, from carboxyl and hydroxyl groups and by elimination of aliphatic structures ${ }^{12}$.

\section{Nitrogen $(\delta N)$}

There are no significant variations in any coal with temperature or coal rank.

\section{Sulphur $(\delta S)$}

There is a direct relationship between total sulphur (St) elimination and temperature increase and an inverse one with coal rank. The evolution of sulphur forms is described later.

\section{Oxygen $(\delta O)$}

At $120^{\circ} \mathrm{C}$ there is a direct relationship between oxygen gain and coal rank. At $150^{\circ} \mathrm{C}$ the increment of oxygen contents is twice or four times greater than that produced at $120^{\circ} \mathrm{C}$. The increases are similar for the four coals after
10 days. At $190^{\circ} \mathrm{C}$ there is a loss of oxygen content in coal $A$ and an increase in the other coals; the oxygen variation correlates with coal rank.

In general, oxygen incorporation increases with rank. This can be explained by taking into account the smaller degree of oxidation of the highest-rank cuals or the larger number of active sites of these coals.

The results obtained relating the loss of weight to the variation of each element indicate the existence of two concurrent processes, the first being the incorporation of oxygen and the second one the elimination of water and carbon oxides ${ }^{13}$. Some functional groups produced by the first process can be eliminated subsequently by the second one. The reaction rates at the temperatures studied seem to favour the elimination reactions at $120^{\circ} \mathrm{C}$ and at $190^{\circ} \mathrm{C}$, whereas at $150^{\circ} \mathrm{C}$ both processes seem to be balanced.

The $\mathrm{E}_{4} / \mathrm{E}_{6}$ ratio is considered to be an indicator of the molecular size ${ }^{7}$, at least, for HA of the same origin. For all the coals, the results presented in Figure 2 show an increase of the $E_{4} / E_{6}$ ratio with the temperature, in agreement with the expected reduction of the HA molecular size and the higher degree of oxidation.

All these studies suggest that the application of the dry oxidation of low rank coals with air is of little value for the production of HA. These coals present a high initial content of labile $\mathrm{HA}$ so the gain produced on the oxidation of non-humic molecules is compensated by the loss of the oxidized HA. The opposite is true for the other studied coals, for which this process could be worthwhile.

With a view to the importance of reducing the sulphur content in coals, a study of the evolution of sulphur forms during dry oxidation was performed. The use of the produced humic acids as fertilizers can be by previous extraction or direct addition of oxidized coals to the soil. 


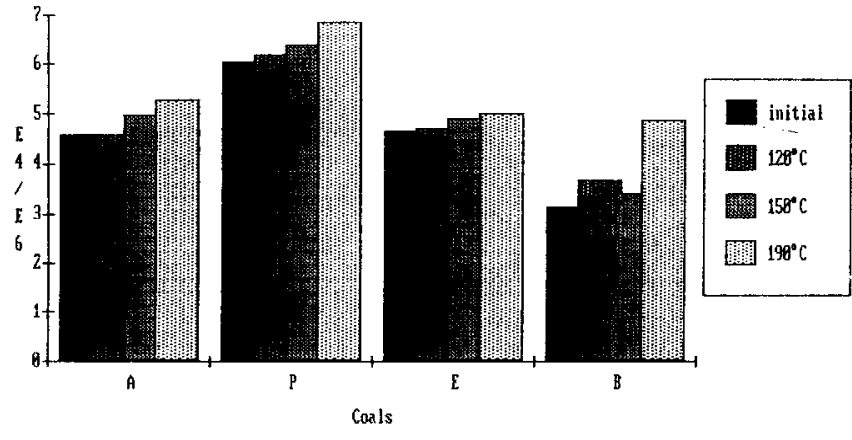

Figure 2 Evolution of $E_{4} / E_{6}$ ratio

Table 4 Evolution of sulphur forms

\begin{tabular}{lllll}
\hline Coal samples & St & Sp & Ss & So \\
\hline A & 6.91 & 0.88 & 0.00 & 6.03 \\
A-120 & 5.98 & 0.81 & 0.41 & 4.76 \\
A-150 & 3.76 & 0.74 & 0.98 & 2.03 \\
A-190 & 3.24 & 0.00 & 1.51 & 1.73 \\
P & 4.91 & 2.06 & 0.68 & 2.17 \\
P-120 & 4.69 & 1.97 & 0.78 & 1.93 \\
P-150 & 4.51 & 1.97 & 1.20 & 1.33 \\
P-190 & 3.07 & 0.63 & 1.67 & 0.80 \\
E & 4.03 & 1.97 & 0.45 & 1.62 \\
E-120 & 3.95 & 1.72 & 0.66 & 1.57 \\
E-150 & 3.57 & 1.67 & 1.07 & 0.83 \\
E-190 & 2.60 & 0.65 & 1.35 & 0.60 \\
B & 7.02 & 1.76 & 0.67 & 4.59 \\
B-120 & 6.62 & 1.66 & 1.01 & 3.96 \\
B-150 & 6.96 & 1.67 & 1.49 & 3.81 \\
B-190 & 6.15 & 0.84 & 2.75 & 2.56 \\
\hline
\end{tabular}

Values in $\mathrm{g}$ of sulphur for $100 \mathrm{~g}$ of initial dry coal

St stands for total sulphur; Sp for pyritic sulphur; Ss for sulphate sulphur, and So for organic sulphur

The sulphur forms, especially the pyrite and sulphate forms, seem to be undesirable in both cases. When HA are extracted, sulphate leads to higher salt concentrations and to a waste of reagent (usually potassium hydroxide). When oxidized coal is added to the soil, pyrite can be oxidized to acidic forms, lowering the soil's $\mathrm{pH}$.

In general, pyritic and organic sulphur decrease and sulphate content increases in the process. The results are shown in Table 4. Total sulphur decreases with increasing temperature; the losses are inversely correlated with the rank. Pyritic sulphur decreases with increasing temperature, but the losses are only significant at $190^{\circ} \mathrm{C}$. These losses are correlated with the increase of sulphate sulphur, which increases with increasing temperature and seems to arise from pyrites. There is only a special case $\left(\mathrm{E}, 190^{\circ} \mathrm{C}\right)$ in which the increment of sulphate sulphur is smaller than the loss of pyritic one. As expected, the loss of pyritic sulphur, and hence the increase in sulphate sulphur is not related to the coal rank. The organic sulphur decreases with incrcasing temperature. The magnitude of the losses is temperature and coal rank dependent; lower-rank coals show significant losses at the lowest temperatures while the highest-rank coal losses are more important for the highest temperatures. This behaviour is in agreement with the expected participation of sulphur in aromatic structures, which increases with increasing rank and requires higher temperatures.

Even though the reduction of sulphur content, especially pyritic and organic forms, is significant, the oxidation of the organic constituents of coal will produce a decrease of the calorific value. Hence the method does not appear to be very convenient for sulphur elimination.

\section{REFERENCES}

Swann, P. D. and Evans, D. G. Fuel 1979, 58, 276

2 Gartsmann, B. B., Sasina, V. N., Rumyantseva, Z. K. et al. Khim. Tverd. Topl. (Solid Fuel Chem.) 1986, 20, 60

3 Umarov, T. Zh. et al. Khim. Tverd. Topl. (Solid Fuel Chem.) $1987,14,42$

4 Chang, K. K., Flagan, R. C., Gavalas, G. R. et al. Fuel 1986, 65, 75

$5 \quad$ Schafer, H. N. S. Fuel 1970, 49, 197

6 Schafer, H. N. S. Fuel 1970, 49, 271

7 Chen, Y., Senesi, N. and Schnitzer, M. Soil Sci. Soc. Am. J. $1977,41,352$

8 Box, G. E. P., Hunter, W. G. and Hunter, J. S. in 'Statistics for Experimenters', John Wiley \& Sons, New York, USA, 1978

9 Massart, D. L., Dikjstra, A. and Kaufman, L. in 'Evaluation and Optimization of Laboratory Methods and Procedures', Elsevier Science Publishers, Amsterdam, 1978

10 Rhoads, C. A., Senftle, J. T., Coleman, M. M. et al. Fuel 1983, 62, 1387

11 Dereppe, J. M., Moreaux, C. and Landais, P. et al. Fuel 1987, 66, 594

12 Anderson, K. B. and Johns, R. B. Org. Geochem. 1986, 9, 219

13 Gethner, J. S. Appl. Spectrosc. 1985, 32, 765 